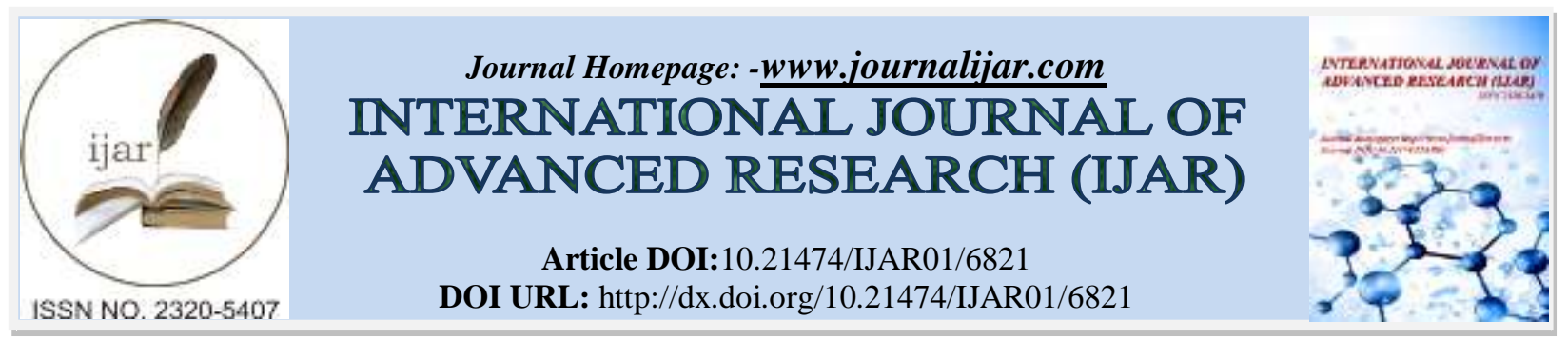

RESEARCH ARTICLE

\title{
ROBOTIC PROCESS AUTOMATION FOR INSURANCE CLAIM REGISTRATION.
}

Sreeja. G. $\mathbf{G}^{\mathbf{1}}$ and M. Shanthini ${ }^{2}$.

Assistant Professor, Department of Computer Science and Engineering KGiSL Institute of Technology.

\section{Manuscript Info}

Manuscript History

Received: 02 February 2018

Final Accepted: 04 March 2018

Published: April 2018

\begin{abstract}
"Insurance claim registration" is used to automatically register the claims with the help of the software. It downloads the claim details with the particular logo of company to avoid downloading the unwanted attachment. The attachment will be in the PDF format and it will be downloaded automatically and stored in a separate folder. The details in the PDF will be verified with the details of the particular person which is in the database (policy number, NCB, black list, sum insured, FIR copy and scanned accident image).If the details is not correct, then only the registration will be done and mail will be sent to the particular insured that some details are not matched. If the details match then the PDF is scraped and with that details will be filled in the claim form automatically. After that, a unique identification for each client will be generated and it will be updated in the excel sheet with the ID .The client gets the notification message once the ID is generated when the registration become success. The main purpose of Robotic process automation (RPA) is to manage the time by completing the work early and efficiently.
\end{abstract}

Copy Right, IJAR, 2018,. All rights reserved.

\section{Introduction:-}

ROBOTIC PROCESS AUTOMATION (RPA) is a software 'robot'. A software robot is a software application that replicates the actions of a human being interacting with the user interface of a computer system. The main purpose of the project intends to introduce more user friendliness in the process of automation. It consume time and to save man power. RPA is software-based; it can be used to perform various tasks. These include maintenance of records, queries, calculations, and transactions. Additionally, any application commonly used by a company can be operated by RPA. For example Citrix, .NET, HTML, and Java are all technologies commonly supported by RPA. Compatible systems include Mainframe Terminals, SAP, Oracle, and many more. Programmable automation means that RPA can be configured to perform almost any rule-based task.

\section{Problem Definition:-}

At present insurance claim registration system more number of claims is sent to the particular insurance company in which the client have insured. The company has to verify each and every claim. The verification of the claim process is done manually. Since the verification process is done manually it consumes lot of time and it needs lot of man power. It may also lead to error in entering the details as it is done manually. In case of any leave of the particular employee who needs to do the specific work of verification then the process may be delayed even more. It may consume time in case of any interference when done manually. 


\section{Related Work:- \\ Four ways RPA is disrupting the insurance market:-}

Robotic Process Automation (RPA) applies various technologies to reduce the manual work and pressure by automating the software robots for satisfying the various core business objectives. By doing this, RPA gives enough amounts of benefits to the workplace to automate routine, standardized tasks in support of an enterprise's knowledge workers. Insurance companies are deploying robotic process automation software to improve operational efficiency around claims, customer service and enrolment and membership.

As the case study details, the insurance company was undergoing a large transformation to move to a Greenfield private cloud infrastructure capable of scaling to 200,000 virtual machines over the next few years. Evidently, the insurer's existing technology environment was too dependent on human-driven manual processes and they were lacking to handle millions of requirements for provisioning, change management \& deployment which are undergoing within the cloud domain. The tools required to manage such a large dynamic infrastructure, in real-time, did not exist in the marketplace.

Customer expectations are increasing day by day. In order to meet those expectations insurance companies must accelerate the digitization of their business processes. Here are some reasons that why Business Professionals of America Business (BPA) is creating a new landscape of opportunity for the insurance market at this time.

\section{Big Savings:-}

The most apparent benefit of RPA is the dramatic reduction in operating costs. Routine works that can be done by multiple human workers can be performed by a single robot within minutes of time.

\section{Driving critical analysis:-}

Beyond delivering cost savings, RPA can drive significant and ongoing business improvement. Once implemented, RPA produces metrics and data that provides critical analytic into operational performance.

\section{Improved Operational Efficiency:-}

With BPA, insurance companies gain a greater operational efficiency, resulting in an increased capacity to manage volume fluctuations in operational processes,

RPA robots are getting revolutionized in all the fields particularly IT business processes and back office work.

\section{Advantages of the Automation process:-}

The work that can be done by humans can be completed within minutes of time by making use of robots. This can save time and costs that can be paid to the workers.

\section{Problem Objective:-}

The main objective of the project is to develop an efficient system, by using RPA. RPA does not require programming skills, Business operations employees - people with process and subject matter expertise but no programming experience - can be trained to independently automate processes using RPA tools within a few weeks. Software robot installed in user's computer, machine or device that tracks human actions and replicates them to perform the complex, redundant and rule-based work which is performed on a daily basis. It is the software application that automates tasks and processes which are otherwise performed only by humans. The important role of robotic automation is to offer improved customer experience and operational excellence by increasing performance, efficiency and agility. Robotic automation helps businesses improve their overall productivity. With its installation in your system, your organization can put its human resources to a much better and efficient use, which will eventually result in increased productivity. Also, RPA takes less processing time. The time taken by RPA to process data and do other rule-based and calculations work is less than 1/4th of what a human resource would take.

\section{Existing System \& Proposed System:-}

\section{Existing System:-}

In existing system, the employee has to check each and every detail individually. Next the verified details have to be entered manually in the application form. Finally the claim id for the registered insured is generated and the notification mail is sent to them by the employee. 


\section{Drawbacks of Existing System:-}

In the existing system the data entry is done manually by the employee. It consumes more time to enter. Human is generally prone to error.

\section{Proposed System:-}

The proposed system consists of 4 categories: Login, verification process, Data Entry and Mailing. The Login can be done by the insured, agent, admin by verifying their details automatically. After that the necessary conditions such as (policy number, black list, and no claim bonus) is verified. Once the details are verified the application form is filled automatically. Then it will send the mail to the particular insured. The rejected claims will be sent to the higher authority for further proceedings.

\section{Experiment:-}

\section{Overview of the Problem:-}

The main purpose of this paper enhances the process done by the insurance agent. Once the claim details is sent by the adjuster to the agent of the insurance company verifying, cross-validating the details of the client and filling in details in the application process is done manually. After the successful completion of the application form the notification is sent to the client; if not the higher authority is notified for the further clarifications.

The following are the 3 main phases involved in this paper.

\section{Validation:-}

This is the foremost step where the adjuster checks in person for the accidental details, verifies the claim details, and sends it to the agent for further processing.

\section{Registration:-}

In this phase, the agent has to verify the details sent by the adjuster and has to fill in the application form. All this process is done automatically.

\section{Notification:-}

On the successful completion of the application form the identity is created and the same client is notified with" successfully registered". If some clarifications are needed or if there arises some issues notification is sent to the higher authority.

\section{Data Flow Diagram:-}

Data flow diagram means of representing a system at any level of details with a graphic network of symbols showing data flow, data process and data source/destination.

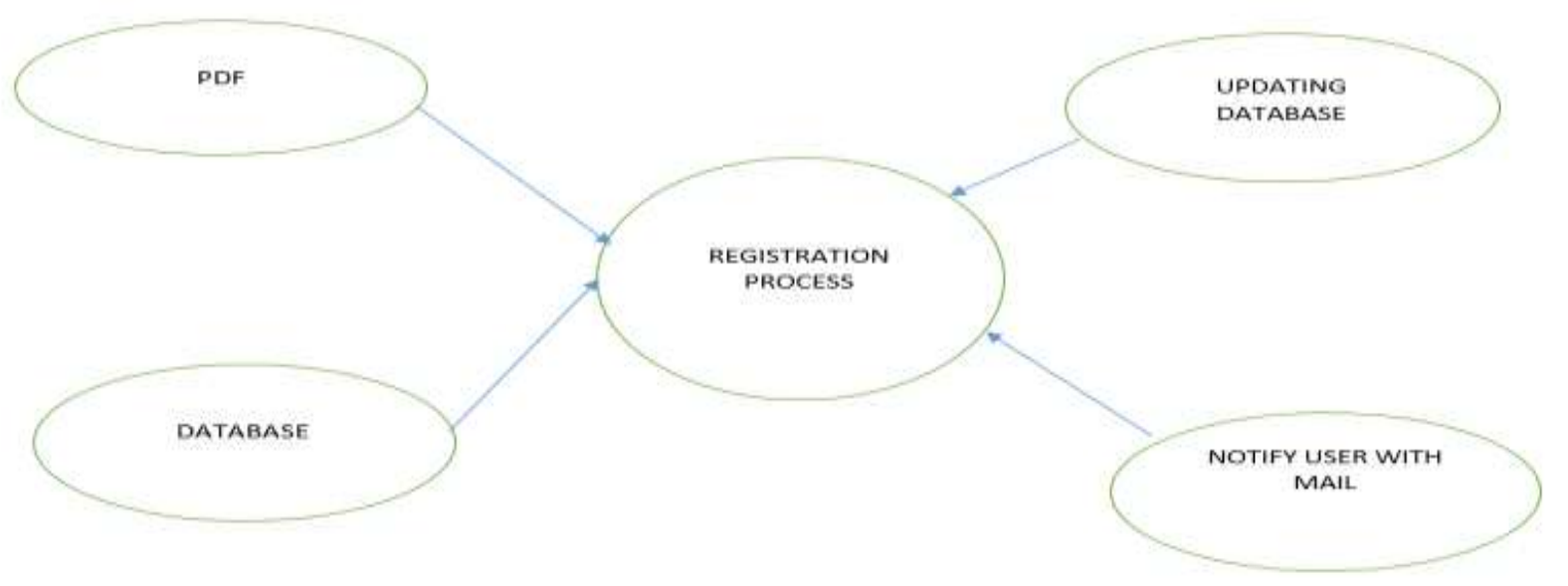

Fig 1:-DFD LEVEL 0 


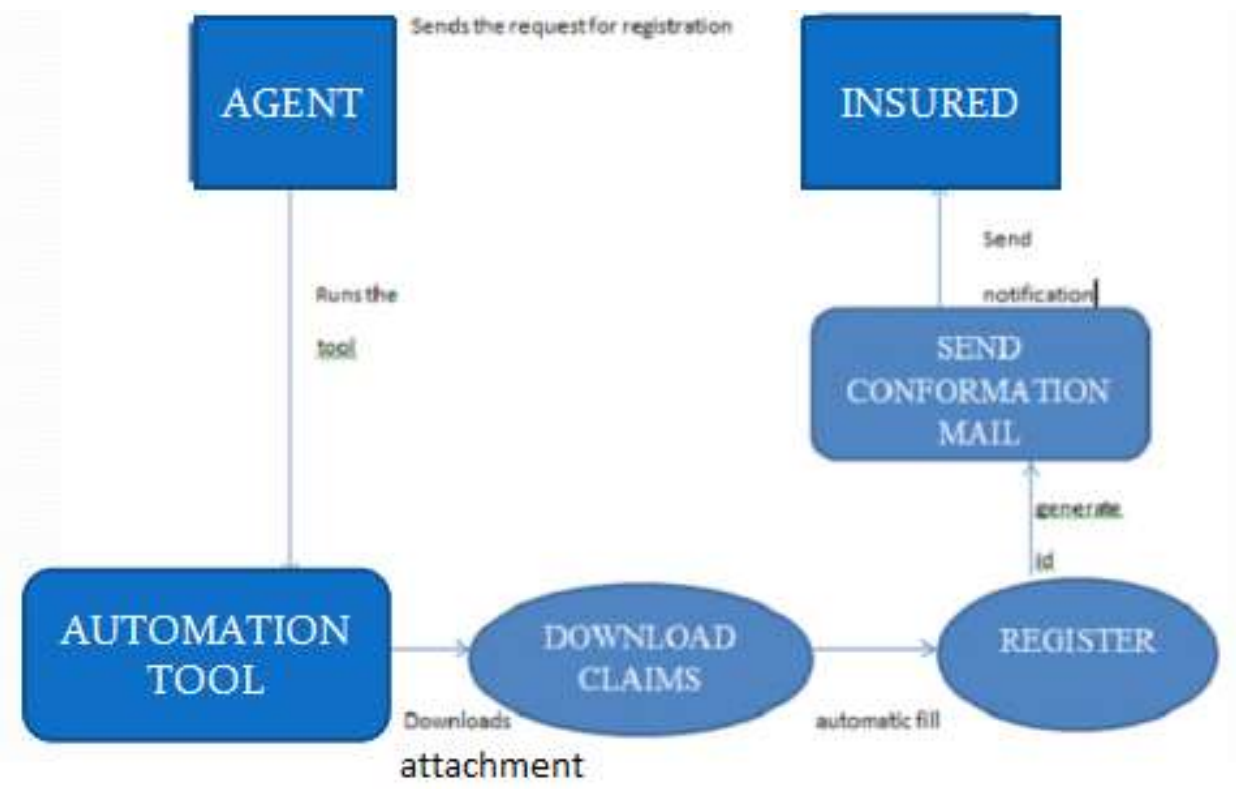

Fig 2:- DFD LEVEL 1

\section{Database Design:-}

Database design is recognized as standard of MIS (Management Information System) and is available virtually for every computer system. The general theme behind a database is to handle information as an integrated completely. Usually centralized access to the Data managing software is called Relational Database.

Table 1:- Policy details

\begin{tabular}{|l|l|l|l|}
\hline S.NO & FIELD NAME & DESCRIPTION & DATATYPE \\
\hline 1. & Policy Number & Policy number & string \\
\hline 2. & Sum insured & Insurance amount & string \\
\hline 3. & Number of claims & No of claims made & string \\
\hline 4. & NCB & NCB amount & string \\
\hline 5. & Mail id & Client mail address & string \\
\hline 6. & name & Client name & string \\
\hline 7. & address & Client address & String \\
\hline 8. & Black list & $\begin{array}{l}\text { Clients who have further } \\
\text { clarifications }\end{array}$ & string \\
\hline
\end{tabular}

Table 2:-Eligible list

\begin{tabular}{|l|l|l|l|}
\hline S.NO & FIELD NAME & DESCRIPTION & DATA TYPE \\
\hline 1. & Policy number & Policy number & string \\
\hline 2. & Claim id & Identity created for client & string \\
\hline 3. & Mail id & Client mail address & string \\
\hline 4. & address & Client number & string \\
\hline 5. & Sum insured & Insurance amount & string \\
\hline 6. & Phone number & Client contact number & string \\
\hline
\end{tabular}

Table 3:-Non-eligible list

\begin{tabular}{|l|l|l|l|}
\hline S.NO & FIELD NAME & DESCRIPTION & DATA TYPE \\
\hline 1. & Policy number & Policy number & string \\
\hline 2. & Claim id & Identity created for client & string \\
\hline
\end{tabular}




\begin{tabular}{|l|l|l|l|}
\hline 3. & Mail id & Client mail address & string \\
\hline 4. & address & Client number & string \\
\hline 5. & Sum insured & Insurance amount & string \\
\hline 6. & Phone number & Client contact number & string \\
\hline
\end{tabular}

\section{Input Design:-}

Input design is one of the most important phases of the system design. Input design is the process of the useroriginated input into a computer to a used format. The aim of the input design is to ensure the maximum possible levels of accuracy and also ensures that the input is accessible that understood by the user. Here the input to the robot is the information sent from the adjuster in the portable document format (pdf) which contains the client details. It has to be correctly transformed into excel format without missing any details since all the further proceedings is based on details in excel sheet. The details should be verified correctly before giving as an input to the robot because an un-valid detail can lead to erroneous result.

\section{Output Design:-}

The output design presents the manipulated data to the end user. The output design acts as medium of communication to the user. A quality output is the one which meets the requirements of the end user and presents the information clearly. In any system results of processing are communicated to the user and to the other systems through outputs. The output design deals with determining how the information is to be displayed for immediate need and also for the hard copy output.

\section{Conclusion:-}

The main process of claim registration is done automatically consuming less time and manpower compared to manual processing of the same. This software helps the insurance agent to accomplish the task of registering the claims of the client as soon as the claim is verified by the adjuster.

This software runs with multiple claims extracting the necessary details to fill in the claim application and notifies the client with information regarding their registration. This reduces the time lapse between the day to day arriving claims and enhances the registration as soon as possible.

\section{References:-}

1. https://academy.uipath.com/lms/index.php?r=player\&course_id=1\#training

2. http://www.simply-access.com/What-Is-Microsoft-Access.html

3. http://www.testingbits.com/robotic-process-automation-and-the-testing-future/

4. https://www.dataentryoutsourced.com/blog/robotic-automation-to-streamline-manual-data-entry-process/

5. https://en.wikipedia.org/wiki/Unsupervised_learning

6. https://www.guru99.com/manual-testing.html

7. Mary Lacity, Leslie Willcocks and Andrew Craig (2015) on Robotic Process Automation at Telefonica O2 LSE Outsourcing Unit paper 15/03; Robotic Process Automation at Xchanging LSE Outsourcing Unit paper 15/03; and chapter on a major utility in Willcocks, L. and Lacity, M.(2016) Service Automation: Robots and the Future of Work (SB Publishing, Stratford).

8. M. J. Matarić, B. Scassellati, Socially assistive robotics, in Springer Handbook of Robotics, B. Siciliano, O. Khatib, Eds. (Springer International Publishing, 2016), pp. 1973-1994.

9. Sutherland, C. (2015) Presentation on The Intelligent Automation Continuum at the HFS Intelligent Automation Webinar, August 27th, 2015.

10. Mary Lacity, Leslie Willcocks and Andrew Craig (2015) on Robotic Process Automation at Telefonica O2 LSE Outsourcing Unit paper 15/03; Robotic Process Automation at Xchanging LSE Outsourcing Unit paper 15/03; and chapter on a major utility in Willcocks, L. and Lacity, M.(2016) Service Automation: Robots and the Future of Work (SB Publishing, Stratford). 